\title{
Discursos en competència en la dreta política valenciana: comunicació i estratègia davant les eleccions autonòmiques de 2019*
}

\author{
Adolfo Carratalá
}

UNIVERSITAT DE VALÈNCIA

adolfo.carratalađuvv.es

ORCID: 0000-0002-9865-9246

\section{Dolors Palau Sampio}

UNIVERSITAT DE VALÈNCIA

dolors.palaufauv.es

ORCID: 0000-0001-9051-0239

Rebut: 28/10/2019

Acceptat: 25/03/2020

\section{RESUM}

Les eleccions autonòmiques de 2019 a la Comunitat Valenciana han plantejat un nou escenari per a l'espectre ideològic conservador, ja que per primera vegada eren tres les formacions que es disputaven aquest vot amb possibilitats d'accedir a les Corts. A més a més, la notorietat aconseguida per l'extrema dreta en el nou panorama polític suposava un desafiament per a la resta de partits. L'objectiu d'aquesta investigació és analitzar com van afrontar la campanya el Partit Popular, Ciudadanos i Vox en un context que els obligava a actuar com a adversaris electorals, però també com a possibles futurs aliats parlamentaris. Aquest treball de recerca examina l'actuació i el discurs de campanya d'aquests tres partits a partir de l'anàlisi del contingut de la cobertura periodística dels diaris Levante-EMV i Las Provincias. L'estudi s'interessa per conéixer els emmarcats preferents, els temes dominants, les ressonàncies culturals i el quadrat ideològic construït per aquestes formacions. Els resultats mostren que l'emmarcat estratègic d'estil de lideratge predominà en la informació d'aquests partits, que van concentrar el seu discurs en temes d'economia i identitat, especialment sobre aspectes ressonants entre l'electorat conservador. Mentre que els temes propis de l'extrema dreta no afecten greument el discurs dels partits majoritaris, Vox tractà d'obrir-se pas distanciant-se del PP, que al seu torn es va veure obligat a reivindicar-se com el partit de referència de la dreta. Cs és el que en més ocasions va fer circular un missatge de possible cooperació entre les tres forces.

Paraules clau: Comunitat Valenciana, eleccions autonòmiques, discurs polític, cobertura periodística, partits de dreta, framing.

\footnotetext{
*Agraïments: Aquest treball s'emmarca en el projecte d'l+D+i «Estrategias, agendas y discursos en las cibercampañas electorales: medios de comunicación y ciudadanos» (referència CSO2016-77331-C2-1-R), concedit pel Ministeri d'Economia i Competitivitat per al període 2017-2020.
} 
ABSTRACT. Competitive Discourses among the Valencian Right Wing: Communication and strategy in the 2019 regional elections The 2019 regional government elections in the Valencian Community led to a new panorama on the Right. For the first time, there were three political parties competing for votes. In addition, the notoriety gained by the Far Right created a new political scene, posing a challenge to other parties. This paper analyses how the Partido Popular, Ciudadanos and Vox managed a campaign in which they were both electoral opponents but also potentially future parliamentary allies. The research examines the performance and campaign discourse of these three parties based on content analysis of the coverage of two newspapers' (Levante-EMV and Las Provincias). The study examines the preferred frames of reference, the main topics, the cultural resonances and the ideological frameworks chosen by these parties. The results showed that news on these parties stressed leadership style and strategy - issues that were highlighted in the parties' discourses given that they resonate strongly with Conservative voters. The issues chosen by the Far Right had little impact on the messages put over by the majority parties. The presence of three right-wing parties meant each tried to differentiate itself from the others. Vox (the furthest on the right, reminiscent of France's Front National] tried to distinguish itself from the more mainstream Partido Popular (PP), which in turn was forced to defend its position as the 'institutional' party of the right. Ciudadanos (Cs) was the right-wing party that spoke most often of potential co-operation among the three forces.

Keywords: Autonomous Community of Valencia, autonomous elections, political discourse, media coverage, right-wing parties, framing.

\section{SUMARI}

Introducció

Dreta ideològica i radicalització del discurs a la política valenciana

L'auge de l'extrema dreta a Europa: missatges i efectes La cobertura periodística de la campanya electoral Metodologia
Resultats

- Emmarcats preferents

- Temes dominants

- Recuperació dels símbols identitaris en la batalla electoral

- El quadrat ideològic de les dretes valencianes

Discussió i conclusions

Referències bibliogràfiques

Autor per a correspondència / Corresponding author: Adolfo Carratalá. Departament de Teoria dels Llenguatges i Ciències de la Comunicació Facultat de Filologia, Traducció i Comunicació Avda. Blasco Ibáñez, 32 - 46010, València (España).

Citació suggerida / Suggested citation: Carratalá, A. i Palau Sampio, D. (2020). Discursos en competència en la dreta política valenciana: comunicació i estratègia davant les eleccions autonòmiques de 2019. Debats. Revista de cultura, poder i societat, 134(1), 133-153. DOI: http://doi.org/10.28939/iam.debats.134-1.8

\section{INTRODUCCIÓ}

Les eleccions autonòmiques a les Corts Valencianes del 28 d'abril de 2019 es van donar en un context inèdit per al centredreta valencià. Per primera vegada des del 1995, el principal partit conservador del País Valencià, el Partit Popular amb Isabel Bonig com a candidata a la presidència de la Generalitat, encarava els comicis amb el rol de líder de l'oposició després de la primera legislatura del Botànic, durant la qual el PSPV-PSOE i Compromís van gestionar el Consell valencià amb el suport parlamentari d'Unides Podem. Per primera vegada, també, el PP veia dibuixat un horitzó en què, en el millor dels escenaris, la possibilitat de recuperar el govern 
de la Generalitat dependria d'un pacte amb les altres dues formacions que aspiraven a fer-se amb el vot del centredreta: Ciudadanos, que concorria per segona vegada a unes eleccions autonòmiques valencianes després d'aconseguir 13 escons en els comicis de 2015, i Vox, que per primera vegada es presentava a la convocatòria electoral amb possibilitats d'entrar en l'hemicicle, ja que en les eleccions anteriors només havia aconseguit el 0,41 \% dels vots (10.184 paperetes).

Les enquestes publicades durant les setmanes prèvies a la jornada electoral apuntaven que, de la mateixa manera que en les formacions d'esquerra, l'única possibilitat que el centredreta tenia de desbancar el Botànic del Consell residia en un pacte entre els tres partits. Diversos sondejos indicaven que el País Valencià podria canviar de color polític després del 28-A, com per exemple assenyalava l'enquesta de SyM Consulting, publicada per Valencia Plaza el 3 de febrer, i que atorgava fins a 54 escons (de 99) a la suma de PP-Cs-Vox, o l'enquesta de NC Report per a La Razón, publicada l'11 de març, que preveia que les tres formacions podrien sumar fins a 51 escons en les Corts, és a dir, majoria absoluta i, per tant, suficient per a investir un/a president/a conservador/a.

Aquestes primeres enquestes resultaren especialment esperançadores per a les formacions de centredreta, i així ho demostra el fet que la realitzada per SyM Consulting per a Valencia Plaza arribara a situar el Partit Popular com la primera força en suport electoral a la Comunitat Valenciana, amb la possibilitat d'aconseguir fins a 23-24 escons, i atorgara a Vox una posició destacada en el parlament valencià, amb una representació que podia estar entre els $14 \mathrm{i}$ els 15 escons. Tanmateix, les eleccions autonòmiques no només generaven incertesa respecte a les possibilitats de la dreta de recuperar l'hegemonia de les Corts, sinó que també significaven una clara disputa per veure si Ciudadanos arrabassava al PP el lideratge d'aquest espectre ideològic, tal com insinuaven algunes enquestes. L'estudi realitzat pel Centre d'Investigacions Sociològiques, publicat l'11 d'abril, deixava oberta aquesta porta en situar Ciudadanos amb 16-19 escons (16\% dels vots) i el PP amb 18-19 parlamentaris (15,4 \% del suport electoral). També el sondeig realitzat per IMOP Insights, fet públic per la cadena COPE en tancar les urnes el 28-A, al-ludia a aquesta possibilitat $\mathrm{i}$ assenyalava que Ciudadanos aconseguiria entre 17 i 18 escons (16,5\% dels vots) i el PP es quedaria amb 16 seients (15,5\% del total dels vots).

Atés aquest escenari de clara incertesa en relació amb les possibilitats del centredreta en la confrontació amb els partits del Botànic, i també respecte a com s'articularia l'hegemonia entre PP, Ciudadanos i Vox, aquesta investigació aborda la manera en què dos dels principals diaris del País Valencià —i els més importants a València-, Levante-EMV i Las Provincias, abordaren la cobertura de l'activitat de campanya d'aquestes formacions, parant atenció als frames que resultaren dominants en aquell tractament, els temes que predominaren, el pes que tingué l'empremta històrica del discurs polític conservador al País Valencià i el mode en què cadascun d'aquests tres partits tractà de posicionar-se en l'escenari mediàtic amb la intenció de dotar-se d'una identitat clarament diferenciada de les altres dues formacions amb què competia pel vot de centredreta a la Comunitat.

Per a poder emmarcar adequadament aquest estudi des d'un punt de vista teòric, cal situar l'acció electoral dels partits valencians de centredreta en una perspectiva diacrònica i sincrònica. Així doncs, els dos següents apartats es dediquen, d'una banda, a abordar com l'anticatalanisme ha estat un element clau de la retòrica de les formacions d'aquest espectre ideològic des de l'anomenada Batalla de València, fenomen que tingué lloc en els anys de la transició i en el qual la participació de l'extrema dreta valenciana resultà clau, i, de l'altra, a explicar el recent creixement que les forces d'ultradreta han tingut al continent europeu i com la seua progressiva influència ha afectat el discurs i l'acció dels partits de centredreta hegemònics. Posteriorment, després de descriure algunes idees clau sobre 
comunicació política en període electoral, l'article exposa l'enfocament metodològic de l'estudi i en descriu els principals resultats obtinguts, així com les conclusions que se'n poden extraure a partir de la contrastació de les hipòtesis.

\section{DRETA IDEOLÒGICA I RADICALITZACIÓ DEL DISCURS A LA POLÍTICA VALENCIANA}

Tot i que un partit d'extrema dreta com Vox no ha arribat al Parlament valencià fins el 2019, el pes polític d'aquesta ideologia i les seues accions han marcat l'evolució de l'autogovern autonòmic des de finals de la dècada dels 70. La irrupció del conflicte identitari en els anys de transició, l'anomenada Batalla de València, es va iniciar amb la connivència dels últims baluards de la dictadura - amb referents com Miguel Ramón Izquierdo i Ignacio Carrau, alcalde de València i president de la Diputació fins a les primeres eleccions municipals de 1979 respectivament- i una complexa confluència d'interessos polítics, socioculturals (Junta Central Fallera, Lo Rat Penat, Acadèmia de Cultura Valenciana) i mediàtics (Las Provincias) que buscaven «la división del pueblo valenciano para atraer a una parte de él a las posiciones de la derecha más reaccionaria» (Sanz, 1982: 76-77), com evidencien les postures compartides a la fi del franquisme i els continguts finalment aprovats. En un moment de concreció dels elements identitaris en l'Estatut d'Autonomia, la patrocinada i tolerada intervenció de l'extrema dreta en l'escenari polític i social (Sanz, 1982; Cucó, 2002), va marcar la denominació del territori, la llengua i la bandera. Com destaca Mira, «qui controla el contingut i significat dels símbols, qui en regula la difusió i l'aprenentatge, controla també la "consciència" que en resulta» (1985: 29).

Historiadors com Cucó han qualificat de «clarament desenfocada» la designació de Batalla de València per a referir-se a la «singular rebel-lió, incivil i antidemocràtica»: "Aquesta "batalla" mai no tingué lloc [...]. Fou una allau de violència induïda, gairebé sempre unilateral [...] que ha contribuït, si més no, a una inflexió profunda i llarga en les terres valencianes dels valors de la cultura i de la democràcia» (Cucó, 2002: 136). Albert i Hernàndez l'associen a «una estrategia de la derecha postfranquista para cortocircuitar el avance de las fuerzas nacionalistas de izquierda y de la izquierda en general» (2011: 6).

L'enfrontament era una opció per a frenar les aspiracions autonomistes i l'accés a un grau d'autogovern major, per la via de l'article 151 de la Constitució, aplicat a les nacionalitats històriques. La politització dels símbols, i en especial l'anticatalanisme, es va convertir en una eina al servei particular d'UCD (Unió de Centre Democràtic) i els seus dirigents. L'estratègia anticatalanista esdevenia el boc expiatori per a frenar el procés autonòmic $\mathrm{i}$, de pas, el PSPV-PSOE, primer partit en vots al País Valencià (Sanz, 1982: 163). Picó i Reig atribueixen a UCD i als seus principals líders a València la responsabilitat d'impulsar un «valencianismo visceral y agresivo» que es recolzava en col-lectius dedicats a boicotejar actes de les incipients institucions democràtiques i en «grupos de reconocida filiación fascista». L'objectiu era «explotar» els sentiments populars contra el «perill català» (1988: 958-961). En aquest context un «moviment sociopolític» com el blaverisme va fer de l'anticatalanisme la seua principal raó de ser (Flor, 2009), revestint-lo d'un «autoctonisme valencianista» que, en essència, «reinventa la tradició i la identitat regional valenciana» (Flor, 2010: 113).

En el foment d'allò que Cucó qualifica de «populismo fascistoide», per part d'una dreta «antiautonomista» que pretenia obtenir rèdits electorals (1983: 84), va fer d'altaveu indispensable el diari Las Provincias i la llavors sotsdirectora, María Consuelo Reyna, com a facilitadora de «l'exitosa penetració social del blaverisme» (Flor, 2010: 121). Aquesta aliança politicomediàtica (Xambó, 1995, 2001; Viadel, 2006; Iranzo, 2011) va ser clau en l'anomenada Batalla de València. «Las Provincias, Reyna i els col·laboradors no tan sols van fer de l'anticatalanisme una implacable croada en la qual oblidaren delibe- 
radament les mínimes regles de l'ètica periodística o la moral pública, sinó que l'ampliaren amb la persecució de personatges públics, actuacions o fets» (Viadel, 2006: 214).

Lluny de quedar-ne reduïdes a l'àmbit dialèctic, les dimensions d'un enfrontament «llarg, complex, virulent; l'acte decisiu d'una guerra» (Mollà i Mira, 1986: 157) van estar acompanyades de múltiples accions violentes entre final dels anys 70 i principi de la dècada dels 80 , moltes de les quals atribuïdes al Grup d'Acció Valencianista (GAV), vinculat a la ultradreta. A les bombes contra intel-lectuals com Joan Fuster i Manuel Sanchis Guarner, s'hi van sumar els atacs a altres defensors de la unitat de la llengua, com la llibreria 3i4 o les agressions i amenaces a treballadors del Centre Territorial de RTVE a la Comunitat Valenciana, a més d'altres formes de violència al carrer. L'estratègia impulsada per UCD i reforçada per l'acció mediàtica, juntament amb la pressió d'entitats vinculades a l'extrema dreta al carrer pretenia boicotejar l'actuació d'uns organismes preautonòmics sense consolidar, amb l'objectiu que la ciutadania deixara de recolzar el procés autonòmic i poder negociar l'Estatut «entre bastidors» (Picó i Reig, 1988: 958-961), com finalment va ocórrer.

\section{L'AUGE DE L'EXTREMA DRETA A EUROPA: MISSATGES I EFECTES}

Actualment, els partits d'extrema dreta tenen un destacat pes electoral en diversos països d'Europa en alguns dels quals fins i tot assumeixen responsabilitats executives. A Polònia, per exemple, el partit Llei i Justícia (PiS) aconseguí el 37,6 \% dels vots en les eleccions de 2015, un suport que el va convertir en la primera força i li va permetre entrar en el Govern. El Partit Liberal d'Àustria (FPÖ), que va aconseguir el 26,65 \% dels vots en els comicis de 2017, o la Lliga Nord italiana, que aconseguí un $17,4 \%$ de recolzament en les eleccions de 2018, també formen part dels executius dels seus països. Destaquen, igualment, partits com el Front Nacio- nal a França (segona força en les eleccions de 2017, amb un 21,3\% dels vots), el Moviment per una Hongria Millor (Jobbik, amb un 19,1 \% el 2018), el Partit Popular Danés (DF, amb un 21,1 \% el 2015) o la formació Alternativa per a Alemanya (AfD, amb un $12,6 \%$ dels vots el 2017).

Tots són exemple de com la ultradreta ha reviscolat en els darrers anys al continent europeu, tot i que el seu creixement progressiu ja suma vora quatre dècades d'història. Durant els primers anys dels 80 , una nova extrema dreta començà a obrir-se pas a alguns països de l'Europa occidental, encara que marcant, malgrat el seu caràcter ultranacionalista, distàncies respecte del feixisme i el nazisme, sobretot perquè no advocava per la supressió de les institucions i de les llibertats democràtiques, tot i la feroç crítica que feia al concepte d'estat del benestar i la defensa de la reducció d'impostos (Rodríguez Jiménez, 2006). Aquestes formacions, encoratjades pel Front Nacional, anaren fent-se espai en els respectius parlaments nacionals (De Lange, 2012), i també al Parlament Europeu, on a poc a poc han anat guanyat posicions des que el partit de Le Pen hi va irrompre amb deu europarlamentaris en les eleccions de 1984 (Gómez Reino, 2009). Des d'aleshores, la dreta radical populista ha esdevingut un actor polític de primer ordre a Europa (Hernández Carr, 2011).

Aconseguir aquest protagonisme ha sigut, en bona part, resultat de posar en circulació un discurs populista amb què els partits d'ultradreta han volgut construir un «nosaltres», amb què s'hauria d'identificar el major nombre possible d'europeus, davant d'un «ells» que, normalment, queda representat per diferents grups que passen a ser una amenaça (Krasteva i Lazaridis, 2016). Les persones immigrants han sigut el principal objectiu d'aquesta estratègia de construcció de «l'altre». Com indica Hernández Carr (2011), la xenofòbia antiimmigrant ha passat a ser el pilar de la mobilització política de tota la dreta radical populista europea. Fins i tot, partits com Alternativa per a Alemanya (AfD), que va nàixer únicament amb l'objectiu de lluitar contra la unió monetària europea enmig de la crisi del deute 
sobirà, reorientà prompte la seua retòrica cap a una postura crítica amb la immigració i centrà la seua campanya comunicativa en missatges de caràcter xenòfob (Schmitt Beck, 2017). El discurs contra la immigració es concreta a través de diversos emmarcats. En algunes ocasions, ho fa a partir de la idea del racisme cultural, en altres, s'articula a través de missatges que vinculen immigració i qüestions de seguretat (Pajnik, Fabbro i Kamenova, 2016). Aquesta darrera fórmula els permet també posar en marxa una altra de les seues principals línies discursives, l'antielitisme, en la mesura que acusen els governs de no fer prou per a protegir les poblacions nacionals. A través d'aquest argumentari antiestablishment (Krasteva i Lazaridis, 2016), les formacions de dreta radical aconsegueixen presentar-se davant l'opinió pública no com a partits clàssics, sinó com a moviments suprapartidistes que volen representar la nació/poble traït pels «politicastres» (Antón Mellón i Hernández Carr, 2016).

A banda de la població immigrant i les elits, el discurs d'aquesta dreta radical també té en la comunitat LGTBI i en la «ideologia de gènere» un altre blanc predilecte. La idea de la família tradicional i l'equació dona-maternitat es troben en la base d'aquests partits (Mayer, Šori i Sauer, 2016). Tot i que, sovint, neguen ser homòfobs i s'expressen a favor de la igualtat entre homes i dones, sobretot en països com Dinamarca o Noruega, també s'oposen a polítiques específiques de gènere, com les quotes o les accions de discriminació positiva, ja que consideren que la igualtat ja està assolida (Meret i Siim, 2013) i argumenten que els col-lectius LGTBI i les organitzacions feministes no són sinó lobbies i moviments ideològics i militants als quals cal fer front (Mayer, Šori i Sauer, 2016). Paradoxalment, aquests partits també es presenten com a màxims defensors de les dones i les minories sexuals quan es tracta d'atacar algunes comunitats d'immigrants o religioses - com ara els musulmans- pel tracte que donen a aquests grups socials (Meret i Siim, 2013).

La creixent presència d'aquestes formacions en l'espai institucional europeu ha provocat canvis no- tables en l'escenari polític, sobretot en la posició que ocupa el centredreta. Com assegura De Lange (2012), des de finals dels 90, els partits majoritaris de caràcter conservador començaren a cooperar amb les formacions de dreta radical en diferents governs nacionals, com va ocórrer a Itàlia, Àustria i, uns anys més tard, a Dinamarca, Noruega i Holanda. Aquest moviment s'explicaria, segons aquest autor, per la voluntat dels partits majoritaris d'abastar posicions de poder des de les quals poder aplicar les seues polítiques, a més de respondre, també, a un càlcul estratègic que busca neutralitzar l'èxit electoral de l'extrema dreta, que cada vegada representa un adversari més evident. La conseqüència és la posada en marxa d'un clar procés de bipolarització en els escenaris polítics nacionals i el desplaçament més a la dreta encara dels principals partits de caràcter conservador en assumptes culturals, com la immigració, la integració i la seguretat, amb l'objectiu de facilitar la formació de coalicions amb la dreta radical. Bale (2003) coincideix en el diagnòstic quan indica que el fet que el centredreta faça de les formacions ultres els seus companys de coalició desemboca en la seua legitimació (passen a ser més respectables) i a una major preeminència de la seua agenda. Un clar exemple el va representar el partit polític liderat per Pim Fortuyn a Holanda, que aconseguí reestructurar l'agenda política del país a partir de la promoció de determinats temes — com ara la gestió de les sol-licituds d'asil— que la resta de partits havien evitat abordar durant molt de temps, la qual cosa el va fer obrir-se pas com una formació respectable enmig d'una societat amb una llarga tradició de progressisme i tolerància (Van der Brug i Mughan, 2007).

Espanya, durant molts anys, ha semblat no veure's afectada per aquest fenomen polític a causa de, entre altres motius, l'excessiva vinculació que l'extrema dreta espanyola mantenia amb el llegat del règim franquista i la monopolització de l'espai electoral potencial de la dreta radical populista per part del partit hegemònic de la dreta espanyola, el Partit Popular (Hernández Carr, 2011). Així, els dos partits principals d'ultradreta d'àmbit estatal, 
Fuerza Nueva i Falange Española de las JONS, han tingut una presència irrellevant en les institucions (Rodríguez Jiménez, 2012). El contagi de l'aparició de la nova extrema dreta a Europa també ha tingut lloc, però en l'àmbit municipal, on alguns partits com ara Democracia Nacional, España 2000 o Plataforma per Catalunya sí que han plantejat estratègies electorals centrades en temes com ara la immigració o la crítica a l'establishment, en sintonia amb la ultradreta europea (Sánchez Duarte i Rodríguez Esperanza, 2013; Rodríguez Jiménez, 2012). Aquest limitat espai d'actuació de l'extrema dreta a Espanya ha vist l'oportunitat d'ampliar-se amb l'impuls que Vox ha aconseguit en els darrers mesos i que es traduí en èxit electoral en els comicis autonòmics andalusos celebrats el mes de desembre de 2018, que el van convertir en la clau per a la formació d'un govern conservador que en desbancà el PSOE després de quasi 40 anys.

\section{LA COBERTURA PERIODÍSTICA DE LA CAMPANYA ELECTORAL}

Els mitjans de comunicació tenen un paper clau en el mode en què els ciutadans accedeixen a la informació política, una funció que s'intensifica durant les campanyes electorals (Esser i D'Angelo, 2006). Tanmateix, la investigació sobre la cobertura periodística d'aquests processos polítics mostra que hi predomina una lògica pròpiament mediàtica que difícilment permet generar opinió pública crítica al voltant dels temes que haurien de preocupar el conjunt de la societat (Cappella i Jamieson, 1996; Trimble i Sampert, 2004). En canvi, allò que els mitjans afavoreixen és una lectura de la campanya des d'un doble punt vista. D'una banda, la campanya sol quedar representada com un joc o una competició entre els partits que hi concorren, la qual cosa implica que la campanya és narrada en termes de guanyadors i perdedors, sovint a partir dels escenaris dibuixats per les enquestes (Aalberg, Strömback, i De Vreese, 2011). D'altra banda, les informacions sobre els partits que participen en els comicis també posen habitualment el focus sobre les estratègies que s'hi empren, més que sobre el que proposen o plantegen, en termes de petició de vot, d'atac als oponents o d'estil de lideratge (Valentino, Beckmann i Buhr, 2001; De Vreese i Semetko, 2002).

La recerca sobre les campanyes, però, també s'ha interessat per conéixer quin pes en l'esfera pública arriben a tenir els temes i les polítiques que les formacions recullen en els programes i que, tot $i$ que haurien de ser l'eix central de discussió abans dels comicis, acostumen a quedar de banda. Així mateix, altres estudis (Valera Ordaz, Carratalá i Palau Sampio, 2017) s'han aproximat a la recerca de la comunicació política en campanya contemplant els partits com a agents mobilitzadors i buscant, per tant, en els seus missatges els frames de diagnosi, i sobretot, de prognosi (Entman, 1993) característics de les organitzacions socials que busquen activar accions col-lectives (Benford i Snow, 2000). En tot cas, treballs recents sobre la comunicació generada pels propis partits polítics conclouen que també ells sotmeten la seua producció discursiva a la lògica mediàtica i, per tant, que aquells frames que els mitjans han fet hegemònics en la cobertura electoral són també els que les formacions empren per a plantejar els seus missatges (Palau Sampio, Carratalá y Valera Ordaz, 2017), un clar exemple de mediatització (Strömbäck, 2008; Mazzoleni i Schulz, 1999).

\section{METODOLOGIA}

Aquesta investigació se centra en l'anàlisi del mode en què els tres principals partits de centredreta que concorregueren a les eleccions autonòmiques de la Comunitat Valenciana del 28 d'abril de 2019 -Partit Popular, Ciudadanos i Vox- van intervenir discursivament en l'espai públic tenint en compte la situació de competència, però també de probable necessitat de pactes posteriors als comicis que s'establia entre ells.

Per poder aproximar-nos al discurs públic d'aquestes tres formacions al llarg de la campanya i descartada 
l'opció de recórrer als missatges publicats en les seues pàgines web perquè no $\mathrm{s}^{\prime} \mathrm{hi}$ han produït actualitzacions d'interés en les de Ciudadanos i Vox, s'ha considerat d'utilitat recuperar les informacions i entrevistes que els tres partits van protagonitzar en dues de les principals capçaleres de la Comunitat Valenciana, el Levante-EMV i Las Provincias, amb una audiència mitjana diària de 197.000 i 101.000 lectors, respectivament, segons les dades de la segona onada de l'Estudi General de Mitjans (EGM) referent a l'any 2019. El període d'anàlisi abasta les dues setmanes de campanya electoral; en concret, s'ha revisat la cobertura que aquests dos periòdics atorgaren als partits de centredreta entre el dissabte 13 d'abril - la jornada posterior a l'inici de la campanya-i el dissabte 27, el dia següent a la seua fi. Cal dir que el dia 19 d'abril, festivitat de Divendres Sant, no hi hagué premsa escrita, com és tradicional a Espanya, per la qual cosa l'anàlisi es limità finalment a 14 jornades i, per tant, a 28 exemplars de premsa.

Malgrat que la rutina productiva habitual en la cobertura periodística de les campanyes electorals comporta la publicació diària d'almenys una peça sobre cadascun dels principals partits en lliça per tal d'informar sobre els actes de campanya que realitzen, no tots els dies hi hagué una peça de cada partit considerat. En alguns casos, no n'hi hagué cap; en altres, més d'una. En total, es recopilaren 77 unitats d'anàlisi, entre notícies, cròniques i entrevistes, 29 de les quals en el diari Levante-EMV i les altres 48 publicades per Las Provincias (Taula 1). La diferència entre el volum de peces entre les dues capçaleres s'explica pel fet que Levante-EMV no atorgà pràcticament cobertura a Vox (només una crònica el dia 26 , en la qual donà compte de l'acte central de campanya d'aquesta formació a la ciutat de València), mentre que Las Provincias en feu un ampli seguiment al llarg del període d'estudi, en què es comptabilitzaren fins a 14 notícies sobre aquest partit.

L'estudi tracta de verificar quatre hipòtesis que orienten l'anàlisi dels materials. En primer lloc,
Taula 1 Composició del corpus analitzat

\begin{tabular}{|l|l|l|l|}
\multicolumn{1}{l|}{} & \multicolumn{1}{c}{$\begin{array}{c}\text { Levante- } \\
\text { EMV }\end{array}$} & \multicolumn{1}{c|}{$\begin{array}{c}\text { Las } \\
\text { Provincias }\end{array}$} & \multicolumn{1}{c|}{ Total } \\
\hline $\begin{array}{l}\text { Partit } \\
\text { Popular }\end{array}$ & 15 & 18 & $\mathbf{3 3}$ \\
\hline Ciudadanos & 13 & 16 & $\mathbf{2 9}$ \\
\hline Vox & 1 & 14 & $\mathbf{1 5}$ \\
\hline Total & $\mathbf{2 9}$ & $\mathbf{4 8}$ & $\mathbf{7 7}$ \\
\hline
\end{tabular}

Font: Elaboració pròpia.

d'acord amb el que ha quedat confirmat en investigacions anteriors (Valentino, Beckmann i Buhr, 2001; De Vreese i Semetko, 2002) i tenint en compte l'escenari de competició de tres forces polítiques per una mateixa franja electoral, es considera que:

H1: El frame dominant en les informacions sobre els partits de dreta serà de caràcter estratègic $\mathrm{i}$, en concret, relacionat amb l'estil de lideratge a causa de la necessitat de cadascuna d'aquestes formacions de postular-se com la principal referència d'aquest espectre ideològic.

En segon lloc, tal com s'ha demostrat en l'estudi de l'impacte que els partits d'ultradreta europeus han tingut sobre formacions majoritàries de centredreta, que han acabat incorporant a la seua agenda els temes que aquells subratllen en el seu discurs, com la immigració i la seguretat (Bale, 2003; Van der Brug i Mughan, 2007), es preveu que:

H2: Els temes que l'extrema dreta ha privilegiat en el seu ascens a Europa en els darrers anys predominaran en les informacions sobre Vox, tot i que també tindran presència en les notícies sobre PP i Cs.

A més a més, tenint en compte com d'útil li ha resultat a la dreta valenciana l'apel-lació a l'anticatalanisme des dels anys de la transició (Sanz, 1982; Flor, 2010), $\mathrm{i}$ atés que, com indiquen algunes recerques recents (Ridaura Martínez, 2016), el rebuig al nacionalisme independentista ha sigut una de les constants en els diferents processos electorals de la Comunitat 
Valenciana, en un moment en què el debat sobre el procés d'independència de Catalunya domina l'actualitat política espanyola, és raonable pensar que:

H3: Els partits conservadors faran ús de la idea d'una amenaça pancatalanista com a ressonància cultural dels seus discursos, conscients del llegat simbòlic de l'anomenada Batalla de València, vinculada al procés independentista català.

Per últim, el context de campanya, i el més que probable escenari de pacte postelectoral entre les forces de centredreta com a única opció per a arribar al govern que dibuixaven les enquestes, permet pensar que la cobertura d'aquests partits reflectirà, en general, una estratègia de bipolarització política observada en altres països europeus com a conseqüència del creixement de forces d'ultradreta (De Lange, 2012) i que, per tant:

H4: Els partits de dreta establiran una línia divisòria més clara respecte a l'esquerra que entre ells, a excepció de Vox, que també atacarà el Partit Popular i Ciudadanos perquè necessita aconseguir representació per primera vegada en les Corts Valencianes.

Per poder verificar aquestes hipòtesis, les 77 peces que conformen el corpus han sigut sotmeses a una anàlisi de contingut que combina tècniques quantitatives i qualitatives. La identificació dels emmarcats preferents en les informacions sobre aquests partits s'ha fet a partir de l'anàlisi dels titulars, una aproximació que ja s'ha demostrat útil en anteriors recerques (Palau Sampio et al., 2017; Carratalá i Palau Sampio, 2019), que han distingit entre frames propis de la dinàmica política (programàtics), fruit de la mediatització (de joc, estratègics) o lligats als fenòmens d'acció col-lectiva (prognosi).

Pel que fa a la resta de dimensions (temes, ressonàncies culturals i identificacions/interpel-lacions entre els partits), s'ha tingut en compte la totalitat del text periodístic, perquè això permetia precisar amb més detall alguns elements significatius. Amb la finalitat de conéixer quins temes van ser abordats en la cobertura electoral dels tres partits conservadors objecte d'estudi, s'han considerat sis tòpics diferents, d'acord amb allò que treballs precedents han assenyalat com a assumptes centrals en el discurs del centredreta i de la nova extrema dreta europea: immigració, gènere/igualtat, elits, seguretat, identitat i economia/estat del benestar (Hernández Carr, 2011; Krasteva i Lazaridis, 2016; Mayer, Šori i Sauer, 2016; Staykova, Otova i Ivanova, 2016). Tant la identificació dels frames preferents als titulars, la dels temes dominants en cadascuna de les unitats que conformen el corpus i la de les fórmules a través de les quals els partits examinats es presenten i interpel-len les altres formacions, es durà a terme a partir d'una anàlisi de contingut quantitativa que permetrà obtenir dades de presència i freqüència.

De manera complementària, l'aplicació de tècniques qualitatives pròpies de l'anàlisi crítica del discurs, emprada amb èxit en investigacions recents sobre el discurs populista de la ultradreta europea (Sauer i Pingaud, 2016), permet abordar l'examen de la presència de ressonàncies culturals (Gamson, 1988), així com reconstruir el quadrat ideològic proposat per cada formació i que es pot entendre com l'autopresentació positiva d'un mateix (mitjançant l'èmfasi d'allò positiu i la minimització dels aspectes negatius) i la presentació negativa de l'altre (en aquest cas, l'adversari electoral), a través de l'estratègia inversa (Van Dijk i Rodrigo Mendizábal, 1999), amb una lògica afavoridora de la dinàmica de polarització política que, com hem vist, s'accentua en general al continent europeu.

\section{RESULTATS}

L'exposició de resultats queda dividida en quatre apartats que es corresponen amb les quatre hipòtesis que orienten la investigació. En primer lloc, es descriuen les dades obtingudes a partir de l'anàlisi quantitativa dels frames dominants en els titulars examinats. Seguidament, s'aborda l'estudi, també quantitatiu, dels temes que apareixen en les informacions analitzades i se n'avalua la major o menor 
presència d'acord amb quin dels tres partits polítics considerats protagonitza la peça informativa. En tercer lloc, s'hi exposen les observacions relacionades amb la incorporació del recurs simbòlic de la Batalla de València en el discurs electoral actual de les tres formacions i, per últim, es recullen els resultats extrets de l'anàlisi del quadrat ideològic que es pot identificar en la comunicació de cadascuna d'aquestes forces al llarg de la campanya.

\section{Emmarcats preferents}

El marc dominant en les informacions sobre els partits de dreta en campanya ha estat el de caràcter estratègic, present en sis de cada deu peces analitzades. Tal com recull la Figura 1, hi predomina el frame lligat a estils de lideratge, en què es marquen de manera important les estratègies en l'exercici del poder, l'actitud dels candidats o el seu comportament, que poden influir en una futura gestió: «Bonig: "Somos el único partido con cabeza, nos avala la gestión"» (LE, 27/04/2019); «Cs importa el conflicto catalán a la Comunidad Valenciana» (LE, 16/04/2019), o «El líder de Vox, en una capea» (LP, 15/04/2019).

Les qüestions lligades a l'estil de lideratge estan presents en gairebé un terç de les informacions publicades al llarg de la campanya, en particular les protagonitzades pel PP (44\%), mentre que tant per a Cs com per a Vox representen un $28 \%$, segons s'observa en la Figura 2.

Figura 1 Frames predominants en la cobertura dels partits de centredreta (en \%)

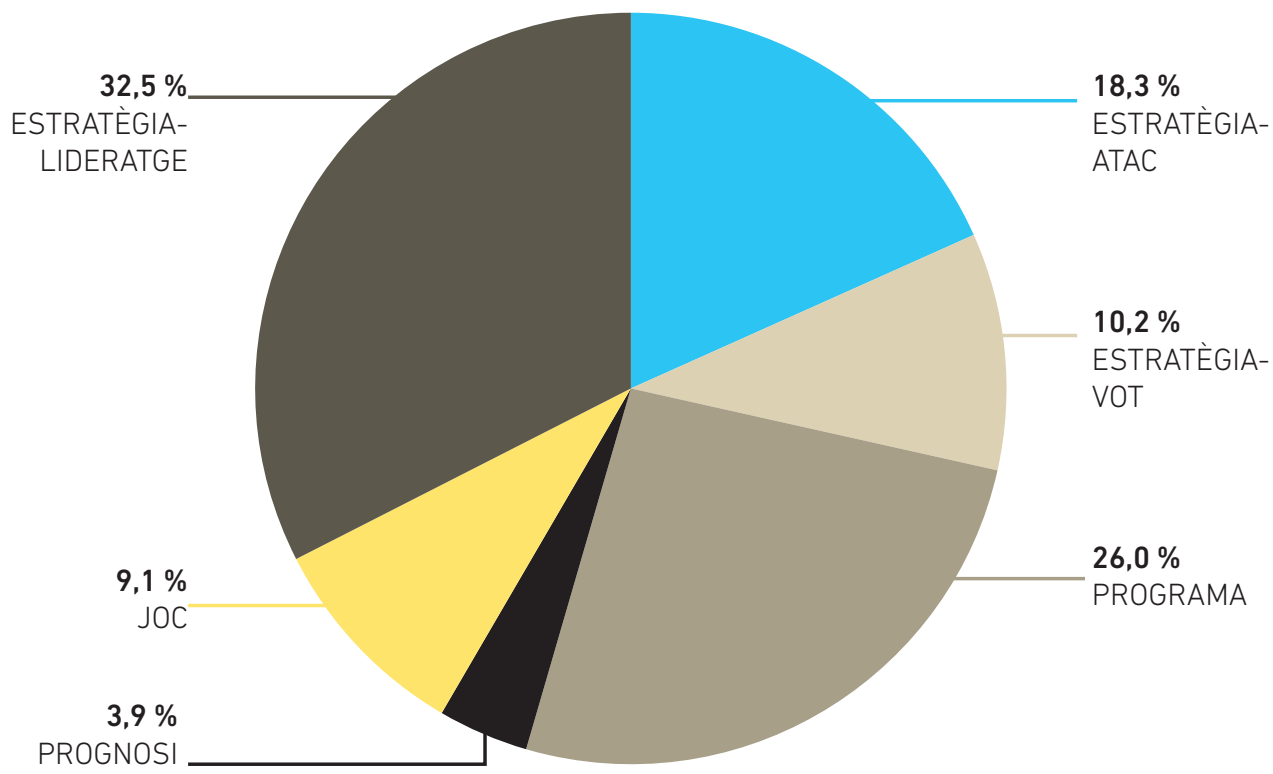


Figura 2 Frames predominants segons el partit polític que protagonitza la informació

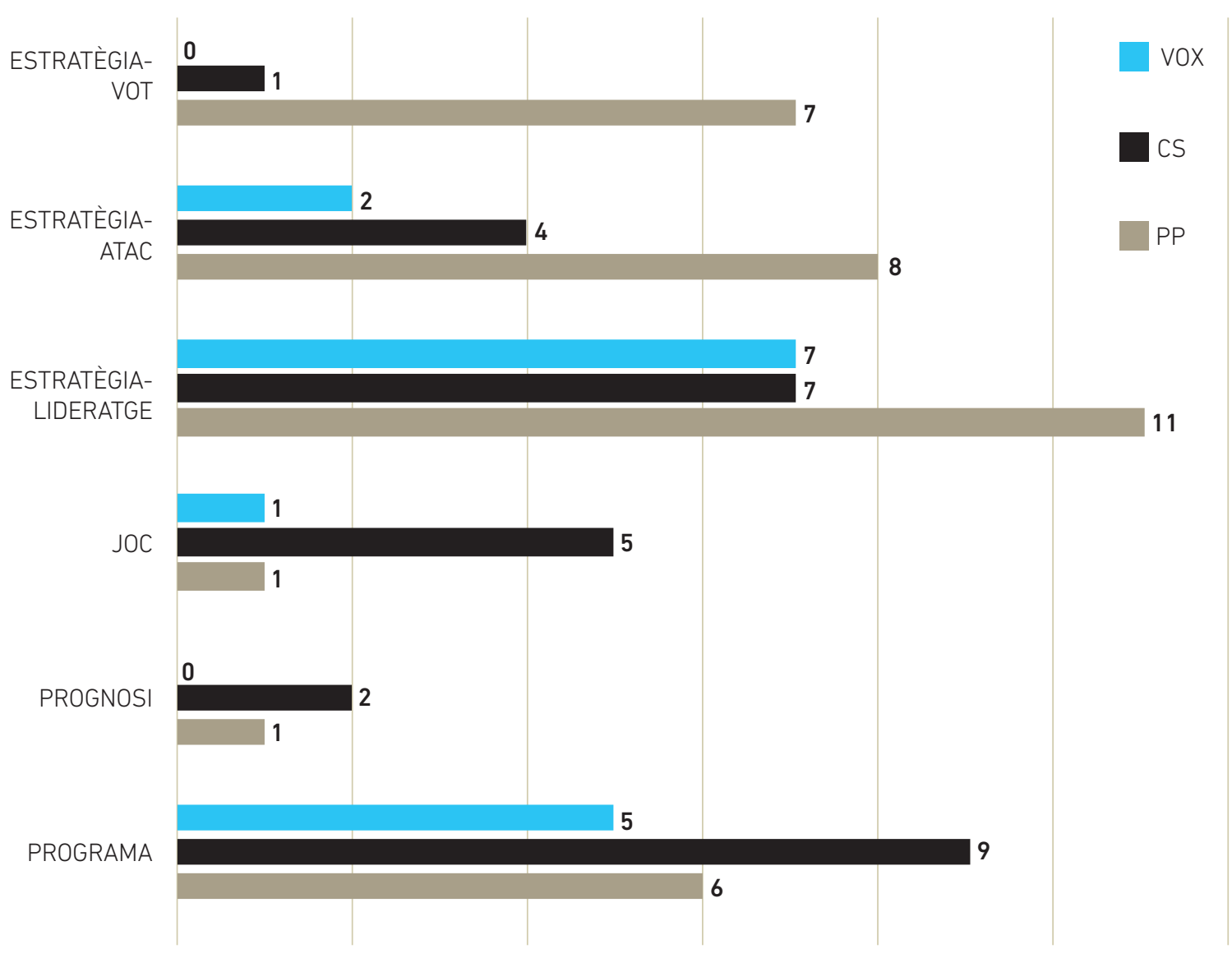

Font: Elaboració pròpia.

Dins de l'emmarcat d'estratègia, l'atac al rival constitueix un reclam en el $18 \%$ de les notícies. Destaca de manera rellevant en les informacions protagonitzades pel PP, que agrupa més de la meitat de peces amb aquest frame (57 \%), amb exemples com aquests: «El PP critica la "cobardía" de Puig por rechazar un cara a cara con Bonig» (LP, 16/04/2019) o «El PP arremete contra la educación catalanista a los niños valencianos» (LP, 21/04/2019). Resulta remarcable que la ma- jor part de les informacions que responen a aquest emmarcat estiguen recollides en les pàgines de Las Provincias. En aquest mitjà es publiquen també les de Vox, que en representen un 14,5 \%: «Vox: Rajoy no tuvo "lo que hay que tener" para dimitir y dejó a Sánchez»(LP, 25/04/2019), i les de Cs, amb un 28,5 \%: «Cantó cuestiona al Botánico por no haber acabado con los barracones» (LP, 16/04/2019). En canvi, Levante-EMV tan sols recull una de les 
Figura 3 Frames predominants segons el mitjà de comunicació

LAS PROVINCIAS

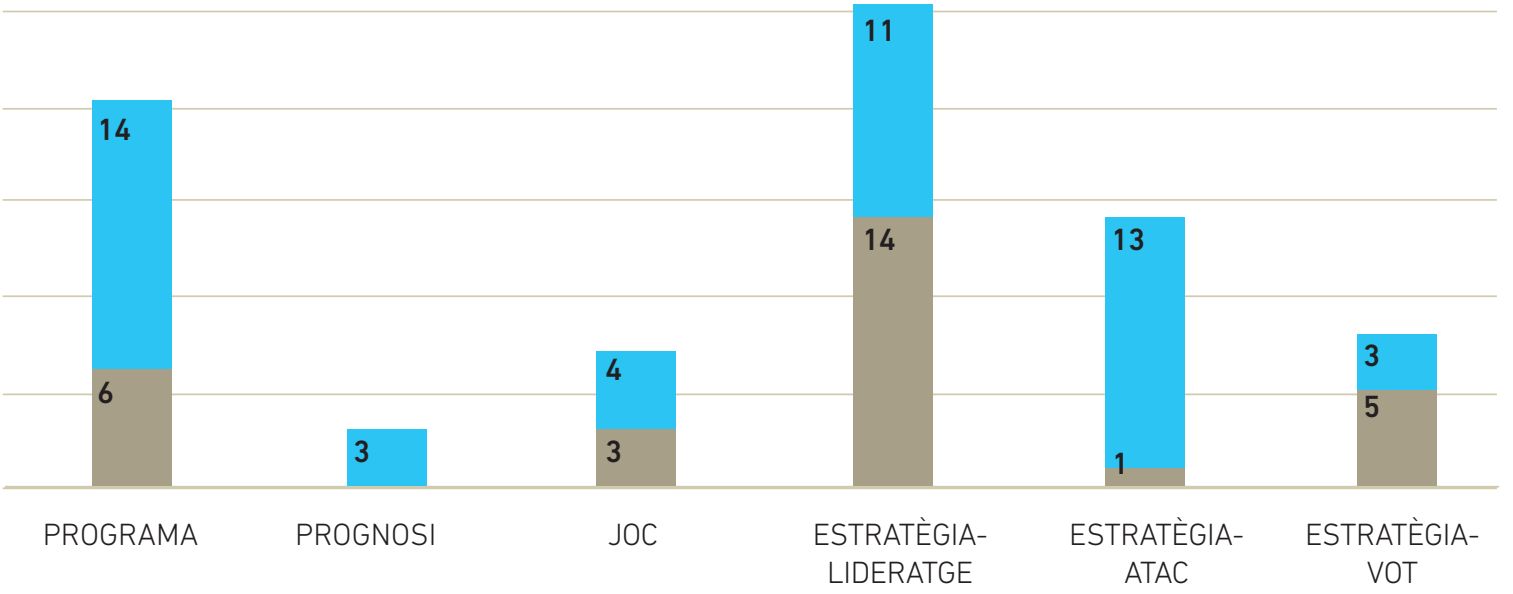

Font: Elaboració pròpia.

informacions d'atac al contrincant, tal com es reflecteix en la Figura 3.

El marc estratègia de vot implica la petició directa de suport o l'apel-lació al vot útil, una opció que apareix en una de cada deu informacions publicades en campanya pels dos diaris principals de la ciutat de València. Com en el cas anterior, el PP presenta un protagonisme especial. De fet, concentra el 87,5\% de les peces amb aquest emmarcat, en particular les encapçalades pel líder del partit a nivell estatal, Pablo Casado, amb una lectura en clau d'evitar que les altres dues forces que pugnen pel seu espai electoral, Cs i Vox, acaben ocupant el seu terreny: «Casado intenta aliviar su retroceso electoral y pide concentrar la derecha en el PP» (LE, 21/04/2019), «Casado llama a votar al PP frente a chaqueteros y a los que no son fiables» (LP, 26/04/2019) o «Casado pide aunar el voto y evitar la fragmentación de la derecha» (LE, 27/04/2019).
El frame programa, lligat a la presentació de propostes programàtiques de la formació, abasta un $26 \%$ de les informacions analitzades. Aquest emmarcat predomina especialment en aquelles peces protagonitzades per Cs, amb quasi la meitat del total (45 \%), seguit pel Partit Popular (30 \%) i Vox (25\%). Entre aquestes propostes s'inclouen notícies que destaquen mesures que cal legislar — «Cs presenta una ley "antienchufes" para las contrataciones públicas» (LE, 23/04/2019); «Bonig anuncia una ley con medidas fiscales para quienes cuidan del hogar» (LP, 13/04/2019)—, propostes que s'aplicaran en cas d'arribar al govern — «Cantó plantea que los comedores escolares estén abiertos todo el año» (LP, 17/04/2019)—o que que es descarten: «Montáñez asegura que su partido no bajará impuestos, sino 24.000 millones en gastos» (LP, 17/04/2019). Com en el cas de l'emmarcat estratègia-atac al contrincant, també aquest té una presència particular en Las Provincias, que concentra set de cada deu notícies. 
Encara que menor que en d'altres estudis, el marc joc, que ve determinat per les referències a l'evolució de la pugna electoral, els suports o possibles pactes, està representat en un 9,1\% de les informacions, amb una clara incidència en aquelles que encapçala Cs. En un panorama electoral obert i sense opcions a majories absolutes, les informacions amb aquest emmarcat giren al voltant de possibles aliances: «Arrimadas ofrece pactar con el PP» (LE, 21/04/2019) o «Cantó insiste en que no pactará con Puig ni aunque se lo pida Rivera» (LP, 13/04/2019).

En canvi, l'emmarcat prognosi, que conté referències simbòliques del partit sobre els grans temes de debat i un pla d'acció a escometre, té un pes residual $(3,8 \%)$ en la mostra i està vinculat a Cs i PP.

Com es pot comprovar en la Figura 4, els emmarcats d'estratègia predominen de forma contundent en les informacions de campanya publicades al llarg de la segona setmana: gairebé el doble que durant els dies d'inici, mentre que les notícies vinculades al programa són les úniques que pesen més en la primera setmana.

\section{Temes dominants}

L'examen de quin tema o temes es tractaven en cadascuna de les unitats d'anàlisi (en una mateixa peça informativa es podia identificar més d'un assumpte) revela que durant la campanya autonòmica valenciana de 2019 les informacions sobre PP, Ciudadanos i Vox van privilegiar temes habituals del discurs polític conservador, però sense atorgar un clar protagonisme a aquells que la ultradreta europea ha fet seus en els últims anys. D'aquesta manera, com s'observa en la Figura 5, els dos assumptes que resultaren hegemònics en el conjunt de la mostra van ser el de la identitat, present en el $47 \%$ de les unitats analitzades, i el de l'economia/ estat del benestar, que apareix en el $42 \%$ del total

Figura 4 Frames predominants en la primera i en la segona setmanes de campanya

1a SETMANA

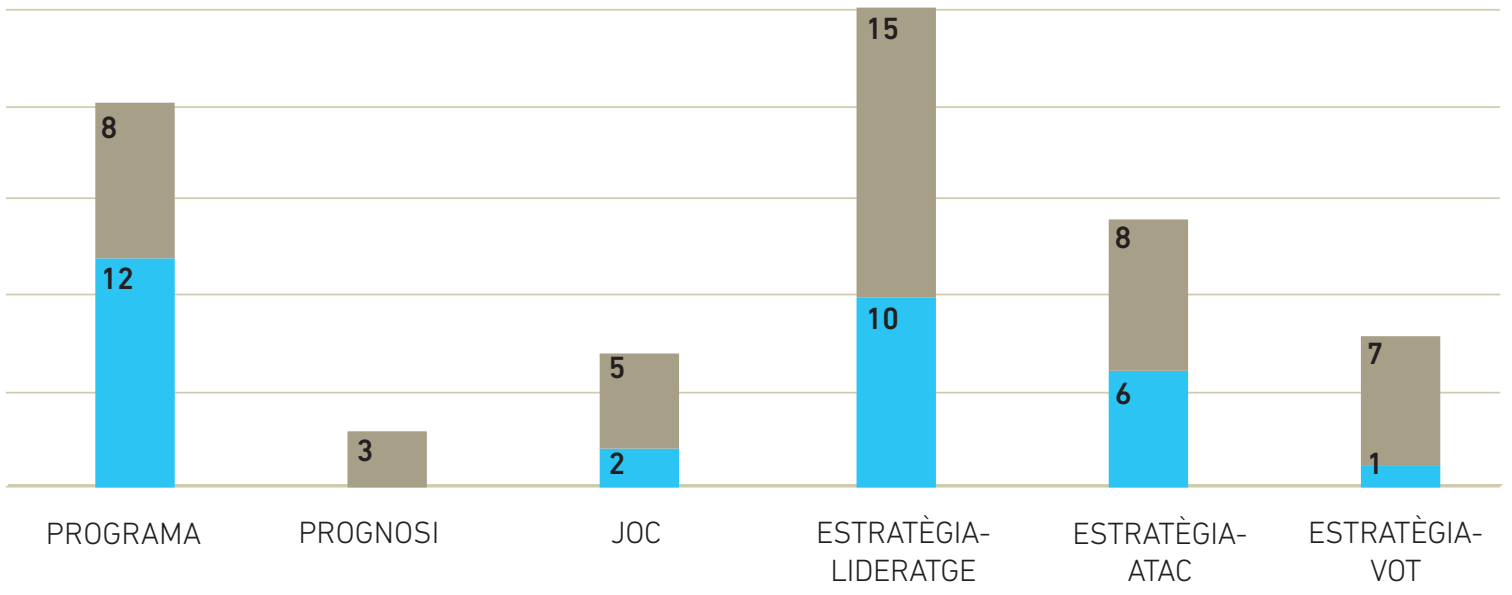


Figura 5 Temes presents en les notícies d'acord amb el partit polític protagonista

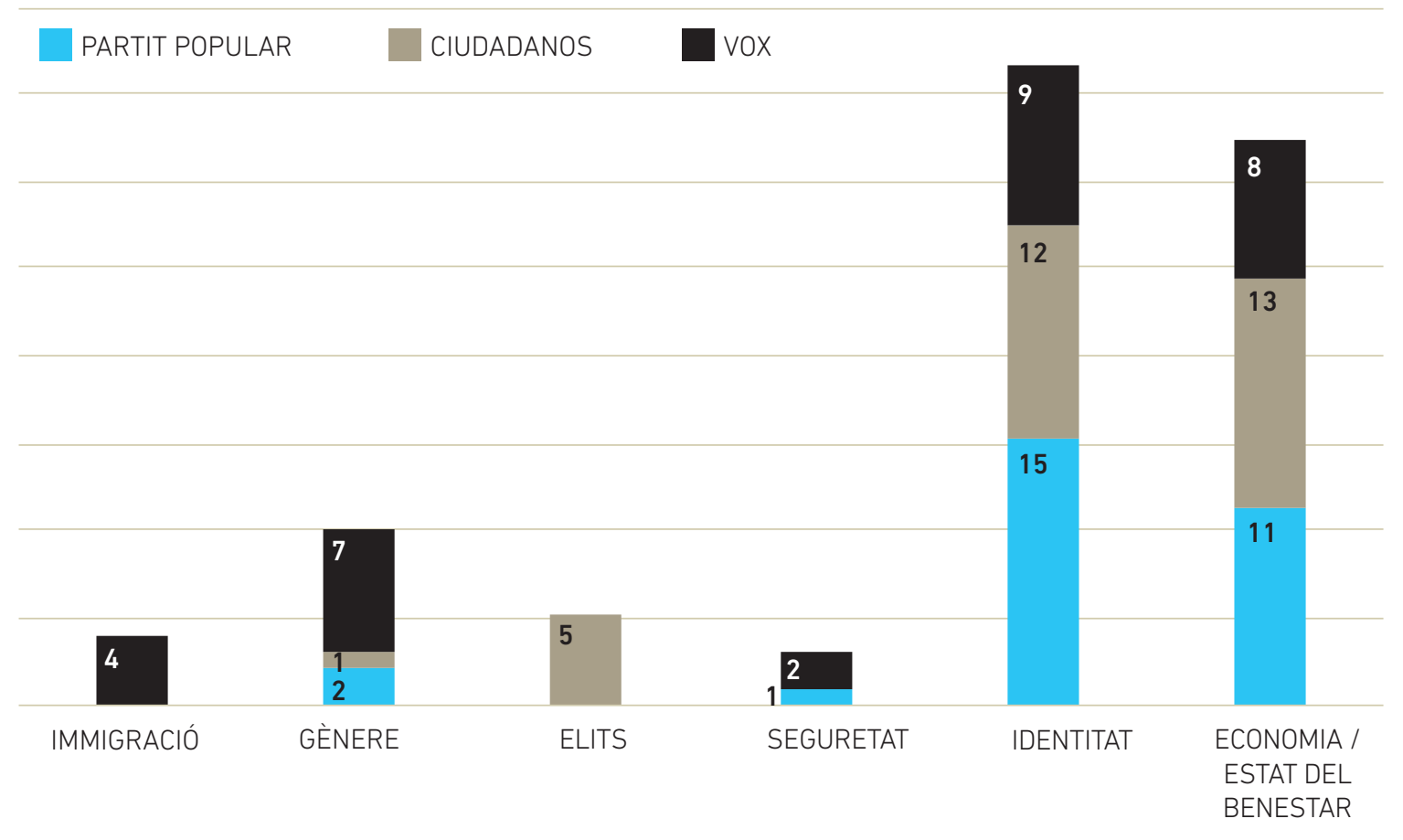

Font: Elaboració pròpia.

de peces. El tema de la identitat va ocupar, especialment, les notícies relatives a Vox (apareix en un $60 \%$ de les notícies en què són subjecte informatiu), PP (45\%) i Cs (41\%).

La manera en què la qüestió identitària és abordada per aquests partits, però, difereix parcialment. Vox promociona el tema per subratllar el caràcter espanyol de la seua formació: de manera explícita afirma la seua lleialtat a Espanya (LE, 26/04/2019) o més subtilment fa referències a la tauromàquia (LP, 15/04/2019). La llengua, d'altra banda, té un paper clau en la manera com els partits conservadors aborden la identitat. Així, Cs fa ús d'aquest vincle en les referències constants a la imposició del valencià sobre el castellà, sobretot a l'escola:
«Hay 205 escuelas de infantil donde los niños no dan castellano ni una sola hora» (LE, 16/04/2019). En altres ocasions, la identitat apareix vinculada a la defensa de la singularitat valenciana davant del suposat perill catalanista que amenaça les tradicions pròpies de la Comunitat, com subratlla sovint el PP: «Bonig promete recuperar la ley de señas de identidad valencianas» (LP, 20/04/2019).

El segon tema dominant és el que aborda qüestions lligades a l'economia i a l'estat del benestar. En aquesta categoria és Vox, de nou, el partit que destaca, ja que fa servir amb més freqüència aquest argument (53\%), seguit de Cs (45\%) i PP (33\%). En general, són dos els missatges que concreten les referències a aquesta matèria. D'una banda, es fa 
al-lusió a la necessitat de reduir els impostos que, des del punt de vista d'aquests partits, ofeguen els valencians. Així ho manifesten Vox - «importante reducción de impuestos» (LP, 13/04/2019)—, Cs — «no los ahogue con impuestos» en referència a l'Administració respecte dels xicotets comerciants (LP, 18/04/2019)— i PP —que ofereix com a primera mesura si guanya «una bajada masiva de impuestos que pasa por la eliminación del de sucesiones y donaciones, y del de patrimonio» (LP, 23/04/2019). D'altra banda, és usual també que les referències a l'economia apareguen lligades a una crítica a l'estat del benestar i, en concret, a la seua estructura institucional i a les despeses que comporta, argument pràcticament monopolitzat per Vox: la defensa d'una «absoluta austeridad» i «la administración tiene que ser pequeña» (LP, 13/04/2019), «España necesita una reforma en profundidad de las administraciones» (LP, 21/04/2019) i «desmantelamiento del sistema autonómico porque supone un despilfarro» (LE, 26/04/2019), en són alguns exemples.

Els altres temes propis de la retòrica electoral de la ultradreta populista tenen una presència menor $i$, majoritàriament, lligada al discurs públic de Vox. Aquest partit és l'únic que aborda el tema de la immigració, tot i que només es recull en quatre de les peces $(27 \%)$, per exemple quan van fer referència a «la creciente invasión islamista por las políticas erróneas europeas sobre el control de las fronteras» (LP, 13/04/2019). De la mateixa manera, Vox incorpora el tema de la seguretat al seu discurs de campanya en parlar de «la legítima defensa» dels espanyols (LP, 13/04/2019; LP, 26/04/2019). També ho $\mathrm{fa}$, tot i que en menor mesura, el PP, quan al-ludeix a la presó permanent revisable (LP, 18/04/2019). Quant a la qüestió de gènere i igualtat, el tres partits aborden el tema, però només Vox ho fa amb freqüència (47 \%) i amb una mirada negativa, en defensar la derogació de la llei LGTBI (LP, 13/04/2019) i la de violència de gènere (LP, 21/04/2019) o en denunciar que «les dicen a nuestros hijos cómo tiene que ser su sexualidad» (LP, 25/04/2019). PP i Cs, en canvi, es mostren defensors en algun moment de la igualtat entre homes i dones, i fins i tot alguna representant es defineix feminista, com la popular Belén Hoyo: «Soy feminista porque entiendo el feminismo como la lucha por la igualdad entre hombres y mujeres» (LE, 18/04/2019). Per últim, pel que fa a les elits i l'establishment, l'anàlisi revela que només Ciudadanos en va fer obertament referència (17\%), d'acord amb la cobertura periodística, defensant una administració «con menos políticos y enchufados» (LE, 14/04/2019), proposant una llei «antienchufes» amb la qual la contratació pública siga per mèrits i no siga suficient «con llevar como currículum el carné de Compromís o el PSC valenciano en la boca» (LE, 23/04/2019) o subratllant que la política es troba molt allunyada de la societat (LE, 24/04/2019).

\section{Recuperació dels símbols identitaris en la batalla electoral}

Hem vist que l'anàlisi de les publicacions sobre els tres partits de dreta durant la campanya prèvia a les eleccions autonòmiques posa de manifest una presència important de referències als símbols identitaris com a eina per a la pugna política, amb ressonàncies clares al que van representar en els anys de l'anomenada Batalla de València. Les al-lusions a l'amenaça catalanista i les imposicions lingüístiques, que van estar en els anys 90 les claus de l'èxit electoral d'Unió Valenciana, hereva del blaverisme, apareixen amb una força renovada en un context de forta competència pel vot de dreta. El pes d'aquesta ressonància cultural es posa de manifest en gairebé un terç $(32,4 \%)$ de les informacions analitzades, en particular les referides a notícies protagonitzades pel PP i Cs.

La situació derivada del procés a Catalunya es converteix en la coartada per a despertar el «fantasma» del catalanisme - «Cs importa el conflicto catalán a la Comunidad Valenciana» (LE, 16/04/2019)_ en les seues diverses manifestacions, tant pel que fa als aspectes lingüístics, qüestionant la unitat de la llengua, com al suposat expansionisme "pancatalanista» (LP, 13/04/2019). Aquesta tesi està present de manera especial en el discurs del PP. Bonig afirma que el nacionalisme «quiere anexionar esta tierra» (LE, 27/04/2019) i Casado parla d'actuar perquè 
«la Comunidad no se convierta en un apéndice de los Países Catalanes»(LE, 27/04/2019), mentre que són constants les referències al fet que el nacionalisme català vol «anexionar esta tierra» o que el govern del Botànic pretén convertir la Comunitat Valenciana en una «colònia» de Catalunya (LE, 23/04/2019), així com l'amenaça d'acabar convertint-se en «catalanes de segunda» (LP, 23/04/2019), en especial en la part central i final de la campanya. En aquesta línia, Vox recondueix el discurs cap a un nacionalisme espanyol — -reaccionaremos firmemente por España y por el Reino de Valencia» (LP, 25/04/2019)_ i a la voluntat de ser «leales a España y nunca al País Valenciano» (LE, 26/04/2019).

El catalanisme es presenta en termes de «peligro real», com afirma en una entrevista el líder de Vox en la Comunitat Valenciana (LP, 13/04/2019) o una de les candidates del PP, que parla de «riesgo real» (LP, 14/04/2019). Les metàfores que segueixen aquest patró veuen el nacionalisme català com «una plaga» que amenaça (LP, 13/04/2019) i advoquen per evitar el risc que «se contagie como la gripe en la Comunitat Valenciana tras cuatro años de tripartito» (LP i LE, 21/04/2019), com destaquen des de Cs. El seu líder en la Comunitat Valenciana parla d'imposició ideològica (LE, 22/04/2019), amb l'escola com el marc d'un «avance del catalanismo en las aulas valencianas» (LE, 24/04/2019), un argument que també fa seu el PP, en referència a la voluntat de lluitar perquè «nadie adoctrine a los niños valencianos con la educación pancatalanista» (LP, 21/04/2019).

\section{El quadrat ideològic de les dretes valencianes}

En primer lloc, cal dir que els diaris analitzats no es referiren pràcticament mai als partits dels quals informaven amb denominacions que no foren el nom oficial de la formació, amb comptades excepcions. Les úniques 11 mostres que observem de fórmules amb les quals les capçaleres al-ludeixen als partits de centredreta sense emprar el nom propi del partit es concentren en referències a Ciudadanos i a Vox. La majoria de casos, però, no impliquen una caracterització ideològica ni política de la formació, ja que es limiten a introduir-les mitjançant expressions com ara «la formación naranja» (LE, 14/04/2019; LP, 22/04/2019) o «el partido naranja» (LE, 23/04/2019; LP, 23/04/2019), en el cas de Ciudadanos, o «la formación que lidera Abascal» (LP, 17/04/2019; LP, 22/04/2019) i «la formación liderada por Abascal» (LP, 18/04/2019), en el cas de Vox. L'únic cas en què s'identifica una voluntat explícita del mitjà per situar i marcar ideològicament una d'aquestes formacions té lloc en la notícia que Levante-EMV dedicà a Vox, al qual es refereix com el «partido de derecha radical» (LE, 26/04/2019).

Per tant, l'assignació d'atributs i la caracterització de les diferents formacions recauen en el propi discurs dels partits. D'una banda, és interessant parar atenció a la manera que cadascuna d'aquestes tres formacions aprofita la campanya per a autodefinir-se i delimitar, en conseqüència, el «nosaltres» amb què volen identificar-se i mobilitzar la ciutadania. L'anàlisi de les notícies apunta que aquest esforç discursiu ocupà especialment l'expressió pública del Partit Popular (un $70 \%$ de les peces relacionades inclouen expressions d'autodefinició), seguit de Vox (40\%) i Ciudadanos (17\%), que destaca per ser el que menys importància atorgà a definir-se a través del seu missatge electoral. El PP, però, ho fa sovint, sobretot per a subratllar la seua experiència al capdavant de les institucions, una idea habitual en els emmarcats de campanya del PP (Valera Ordaz et al., 2017) i que Bonig repeteix tant en entrevistes, com ara la publicada per Las Provincias el 23 d'abril («Somos un valor seguro. Somos el partido de la gestión y lo hemos demostrado sacando a España dos veces de la crisis») com en actes electorals: «Somos el único partido con cabeza, nos avala la gestión» (LE, 27/04/2019). Vox, pel seu compte, tracta de presentar-se com una força nova i valenta amb la qual es pot sentir identificada la gent comú: «Somos la voz alta, clara, firme y sin complejos de esa España que trabaja, que paga sus impuestos» (LP, 14/04/2019) i «hemos venido a la política para cambiar la política, para hacer un verdadero servicio público» (LP, 16/04/2019).

Juntament amb la determinació del «nosaltres», els partits analitzats dedicaren bona part del seu discurs 
de campanya a identificar els «altres», és a dir, els adversaris electorals. Com és lògic, en moltes ocasions els tres partits estudiats intentaren marcar distàncies amb l'esquerra, habitualment al-ludida com «el tripartito», «el Botànic», «la coalición sanchista» (fórmula emprada amb regularitat per Bonig per a referir-se al Govern PSPV-Compromís) o «el PSC valenciano» (expressió pròpia de Cantó). Aquestes referències a l'esquerra, sempre negatives, van ser recollides en un $73 \%$ de les notícies protagonitzades pel PP, en un $62 \%$ de les informacions relatives a Cs i en només una de cada tres peces dedicades a Vox.

Tanmateix, resulta més interessant observar com els partits de centredreta construeixen un «ells» a partir d'un dels altres partits amb els quals comparteixen nínxol electoral. Aquesta operació discursiva també es recull en un notable nombre de les peces examinades i té una presència equivalent en les notícies de les diferents formacions: apareixen en un $45 \%$ de les peces de PP i Cs, i en un $40 \%$ de les dedicades a cobrir l'activitat de Vox. En el cas del Partit Popular, observem que el més habitual és que interpel-le conjuntament a Cs i Vox, com passa en 10 peces - «El voto a Vox puede ser un voto a Pedro Sánchez. Y el voto a Ciudadanos, como son bastante chaqueteros, nunca sabes donde puede terminar» (LP, 14/04/2019) o «La veleta naranja y los verdes con pistola» (LP, 23/04/2019)—, o únicament a Cs, com s'observa en cinc notícies, on són definits com a «bisagristas» (LP, 24/04/2019) o com una formació disposada a pactar amb els socialistes (LE, 20/04/2019; LP, 23/04/2019).

Ciudadanos, pel seu compte, centra en el PP les referències a la dreta, com es veu en nou peces, on incideix en identificar-lo amb el PSOE — «Es muy complicado pactar con el PSOE o con el PP porque son partidos que han cedido siempre que lo han necesitado ante el nacionalismo» (LE, 22/04/2019)_ o en subratllar la relació que mantenen amb la corrupció — «El PP ensució la imagen de la Comunitat, nos robó, nos creó una deuda absolutamente insoportable» (LP, 13/04/2019). També al-ludeix tant a PP com a Vox, però de manera que les formacions no ocupen el lloc central del discurs sinó els seus votants: «Yo puedo entender al votante de Vox porque está cabreado, cansado y disgustado con la clase política, pero a esta persona hay que decirle que hay otra opción de centro» (LP, 22/04/2019) i «Yo entiendo el cabreo de muchos votantes de Vox, que primero fueron decepcionados con un PP que robó, gestionó mal nuestro dinero y manchó la imagen de la Comunitat» (LP, 24/04/2019).

D'altra banda, Vox al-ludeix amb regularitat exclusivament al PP — «Votar a ellos es seguir en el estado del bienestar de los políticos, en la corrupción, en la hipocresía» (LP, 13/04/2019) i, en menor mesura, interpel-la a PP i Cs: «Derechita cobarde», «Seguro es que no tienen valor», «La derechita naranja» o "¿A dónde? ¿Hoy sopla el viento del sur o del norte? ¿Qué dicen las encuestas?» (LP, 26/04/2019).

Només en cinc ocasions, els partits de centredreta semblen atenuar la divisió política entre ells i construir un quadrat ideològic on els tres, o almenys dos d'ells, poden quedar sota el paraigües d'un «nosaltres» comú, especialment en la recta final de campanya i majoritàriament de la mà de Ciudadanos, tal com va fer Arrimadas durant un acte a València — «Le tiendo la mano al PP... y le pido a Pablo Casado que espabile y piense cómo sumar con nosotros para echar a Sánchez» (LE, 21/04/2019)—o Cantó, que valorà positivament el pacte signat a Andalusia en una entrevista: «Yo espero no tener que pactar con otro partido que no sea el PP para reeditar un pacto a la andaluza» (LE, 22/04/2019).

\section{DISCUSSIÓ I CONCLUSIONS}

Els resultats obtinguts de l'anàlisi permeten concloure que el discurs electoral de les tres formacions valencianes de centredreta amb possibilitats d'obtenir representació a les Corts va ser dissenyat d'acord amb un context nou que dibuixava un escenari de clara competència -i més moderadament de possibles futures aliances- entre els tres partits. Aquest panorama sembla haver impactat de 
manera molt més directa sobre el mode en què el Partit Popular i Vox van plantejar els seus missatges públics durant els 15 dies de campanya, i segons ho van recollir les dues capçaleres examinades.

Com ja s'ha comprovat en nombroses recerques prèvies, també la cobertura periodística d'aquesta campanya va privilegiar els emmarcats propis de la lògica mediàtica, presents fins en el $70 \%$ de les unitats d'anàlisi que formen la mostra. En concret, ha estat el frame estratègia el que ha resultat preeminent en el tractament informatiu de les tres formacions objecte d'estudi i, de manera singular, el que fa referència a l'estil de lideratge dels diferents actors polítics, que permetria corroborar la primera de les hipòtesis apuntades en aquest treball. La necessitat de fer del lideratge un factor clau del missatge electoral sembla molt destacada en les informacions vinculades amb el PP, probablement per la necessitat que tenia aquesta formació de presentar-se com l'única capaç de disputar-li el govern a l'esquerra, atés que, per primera vegada des de feia dècades, la seua hegemonia en l'espectre ideològic conservador valencià es veia qüestionada per algunes enquestes. Això explicaria, igualment, la importància que tingué en la seua actuació electoral la petició del vot útil de la dreta, concentrat en les seues sigles, per evitar una dispersió del vot i una possible segona posició entre les tres formacions que es disputaven l'electorat de centredreta.

Pel que fa als temes presents en les informacions analitzades, es pot concloure que aquells assumptes promocionats amb força per la nova extrema dreta europea en els darrers anys a través del seu discurs populista encara no dominen clarament el missatge del centredreta a la Comunitat Valenciana, tot i que sí que són claus en les notícies referents a Vox, de manera molt específica la immigració i les qüestions d'igualtat i de gènere. La segona hipòtesi, per tant, només es confirma parcialment. Els temes més repetits (identitat i economia/estat del benestar) són, així mateix, especialment recurrents en les notícies sobre Vox, encara que també tenen una important presència en les informacions sobre les altres dues formacions. En aquest sentit, i malgrat que PP i Cs no han adoptat, de moment, part del discurs de la ultradreta sobre temes d'immigració i igualtat, sí que s'observen aproximacions en temes d'economia (Vox-Cs) i identitat (PP-Vox), que se sumarien també a l'argument de la seguretat. A més a més, resulta significatiu que un dels temes notablement promocionats per la nova extrema dreta europea (Hernández Carr, 2011), l'antiestablishment, estiga només present de manera explícita en informacions protagonitzades per Ciudadanos, probablement perquè es consideren, malgrat sumar ja uns quants anys d'història, un nou partit que mira d'erradicar el bipartidisme tradicional amb la incorporació de professionals de la societat civil. Eixe factor aproximaria el missatge d'aquest partit a l'estil populista de la ultradreta europea.

La tercera hipòtesi, relacionada amb el pes que la Batalla de València té en el discurs d'aquestes formacions com a ressonància cultural, es confirma només en els casos de PP i Cs, ja que s'identifica en una de cada tres peces vinculades a aquests partits. El primer d'ells recupera així una de les claus electorals de la dreta conservadora del País Valencià (Ridaura Martínez, 2016), mentre que Cs aprofita el seu valor simbòlic, perquè ho considera coherent amb la seua ferma oposició al nacionalisme català, un dels principis impulsors del partit i, probablement, una de les claus que expliquen que haja anat sumant suport electoral en els últims anys a Catalunya, i també a la resta de l'Estat. Com s'ha vist en els resultats, l'advertència d'una identitat valenciana en situació d'amenaça, ressonant amb els discursos enarborats per la dreta valenciana dels anys de la transició, es reprén gràcies al protagonisme que el procés independentista català té en l'actualitat política. Aquesta compta amb el recolzament legitimador de mitjans com Las Provincias, clau en l'anomenada Batalla de València, i que en els darrers anys ha demostrat una ferma i oberta actitud d'oposició i crítica al sobiranisme a Catalunya (Xicoy, Perales García i Xambó, 2017). La idea del «perill catalanista» no hi és, però, en el missatge electoral de Vox, en la mesura que l'ús d'aquesta 
retòrica significaria una suposada defensa de símbols i tradicions valencianes que contradiria aspectes vertebrals de la seua lògica política, ja que la formació respon al perfil ultranacionalista comú a molts partits de la nova extrema dreta europea.

Pel que fa a la construcció del quadrat ideològic d'aquestes formacions, resulta d'interés subratllar tres qüestions. La primera, el fet que, a diferència d'allò que fan PP i Cs, Vox concentre la construcció de «l'altre» al voltant de les dues formacions conservadores amb les quals competia en termes electorals, ja que apareixen molt més que l'esquerra en els seus discursos. D'altra banda, és significatiu que siguen sobretot PP i Vox els que facen un notable esforç comunicatiu per recordar o explicar a l'elec- torat qui són (Cs ho fa en molt menor mesura), la qual cosa podria interpretar-se com la voluntat de seduir el mateix perfil de votant i fer-se amb el seu suport. És, per tant, entre ells dos on es concentra la competència discursiva. Per últim, els missatges que evidencien una actitud més oberta a possibles pactes futurs es troben lligats a Ciudadanos, que, malgrat les crítiques que també adreça al PP, en més d'una ocasió l'incorpora sota un «nosaltres» comú. Al mateix temps, també tracta de mostrar-se empàtic amb els votants de Vox, no amb la formació a la qual pràcticament ignora en el seu discurs. La quarta i última hipòtesi, per tant, quedaria confirmada, ja que s'observa que aquesta actitud de distanciament respecte de PP i Cs és més recurrent en Vox, en lloc de privilegiar l'antítesi en relació a l'esquerra.

\section{REFERÈNCIES BIBLIOGRÀFIQUES}

Aalberg, T., Strömback, J. i De Vreese, C. H. (2011). The Framing of Politics as Strategy and Game: A Review of Concepts, Operationalizations and Key Findings. Journalism, 13(2), 162-178.

Albert Rodrigo, M. i Hernàndez i Martí, G. M. (2011). La identidad en lucha: Iniciativas civiles culturales ante el conflicto identitario valenciano. Papeles del CEIC, 66, 1-41.

Antón Mellón, J. i Hernández Carr, A. (2016). El crecimiento electoral de la derecha radical populista en Europa: Parámetros ideológicos y motivaciones sociales. Política y Sociedad, 53(1), 17-28.

Bale, T. (2003). Cinderella and her Ugly Sisters: The Mainstream and Extreme Right in Europe's Bipolarising Party Systems. West European Politics, 26(3), 67-90.

Benford, R. D. i Snow, D. A. (2000). Framing Processes and Social Movements: An Overview and Assessment. Annual Review of Sociology, 26, 611-639.

Cappella, J. N. i Jamieson, K. H. (1996). News Frames, Political Cynicism, and Media Cynicism. The Annals of the American Academy of Political and Social Science, 546, 71-84.

Carratalá, A. i Palau Sampio, D. (2019). Entre el activismo y la mediatización: Encuadres de partidos y prensa en la campaña catalana de 2017. Revista de comunicación, 18(2), 73-91.

Cucó, A. (1983). Papers públics. València: Fernando Torres Editor

Cucó, A. (2002). Roig i blau: La transició democràtica valenciana. València: Tàndem Edicions.

De Lange, S. L. (2012). New Alliances: Why Mainstream Parties Govern with Radical Right-wing Populist Parties. Political Studies, 60(4), 899-918.

De Vreese, C. H. i Semetko, H. (2002). Cynical and Engaged: Strategic Campaign Coverage, Public Opinion, and Mobilization in a Referendum. Communication Research, 29(6), 615-641.

Entman, R. (1993). Framing: Toward Clarification of a Fractured Paradigm. Journal of Communication, 43(4), 51-58.

Esser, F. i D’Angelo, P. (2006). Framing the Press and Publicity Process in US, British, and German General Election Campaigns: A Comparative Study of Meta Coverage. The International Journal of Press/Politics, 11(3), 44-66. 
Flor, V. (2009). L'Anticatalanisme al País Valencià: Identitat i reproducció social del discurs del "blaverisme" (Tesi doctoral). Universitat de València, Comunitat Valenciana.

Flor, V. (2010). La instrumentalització mediàtica de la identitat valenciana: El discurs anticatalanista de Las Provincias (1978-1999). Arxius de Sociologia, 23, 113-122.

Gamson, W. A. (1988). Political Discourse and Collective Action. En B. Klandermans, H. Kriesi i S. Tarrow (ed.), From Structure to Action: Social Movement Participation across Cultures (p. 219-244). Greenwich, CT: JAI Press.

Gómez Reino, M. (2009). Las elecciones europeas de 2009 y el espectro de la extrema derecha. Análisis del Real Instituto Elcano, 101, 1-5.

Hernández Carr, A. (2011). La derecha radical populista en Europa: Discurso, electorado y explicaciones. Revista Española de Investigaciones Sociológicas, 136(1), 141-160.

Iranzo, A. (2011). El papel de la prensa diaria durante la transición a la democracia en Valencia (1976-1982) (Tesi doctoral). Universitat de València, Comunitat Valenciana.

Krasteva, A. i Lazaridis, G. (2016). Far Right: Populist Ideology,'Othering' and Youth. En M. Ranieri (ed.), Populism, Media and Education: Challenging Discrimination in Contemporary Digital Societies (p. 9-25). Abingdon, Nova York: Routledge.

Mayer, S., Šori, I. i Sauer, B. (2016). Gendering 'the People': Heteronormativity and 'Ethno-masochism' in Populist Imaginary. En M. Ranieri (ed.), Populism, Media and Education: Challenging Discrimination in Contemporary Digital Societies (p. 84-104). Abingdon, Nova York: Routledge.

Mazzoleni, G. i Schulz, W. (1999). «Mediatization» of Politics: A Challenge for Democracy? Political Communication, 16(3), 247-261.

Meret, S. i Siim, B. (2013). Gender, Populism and Politics of Belonging: Discourses of Right-wing Populist Parties in Denmark, Norway and Austria. En B. Siim i M. Mokre (ed.), Negotiating Gender and Diversity in an Emergent European Public Sphere (p. 78-96). Londres: Palgrave Macmillan.

Mira, J. F. (1985). Crítica de la nació pura: Sobre el símbols, les fronteres i altres assaigs impetuosos. València: Eliseu Climent.

Mollà, D. i Mira, E. (1986). De impura natione. València: Eliseu Climent.

Pajnik, M., Fabbro, F. i Kamenova, D. (2016). Ethno-nationalism and Racial Capitalism in Populist Framing of Migrants as a Threat. En M. Ranieri (ed.), Populism, Media and Education: Challenging Discrimination in Contemporary Digital Societies (p. 67-83). Abingdon, Nova York: Routledge.

Palau Sampio, D., Carratalá, A. i Valera Ordaz, L. (2017). Mediatización y encuadres de campaña: Análisis comparado de la información de partidos y medios en las elecciones generales de 2015. El profesional de la información, 26(4), 602-610.

Picó, J. i Reig, R. (1988). Crisis final del franquismo y transición a la democracia. En M. Cerdà, (dir.), Historia del pueblo valenciano, III (p. 945-964). València: Levante.

Ridaura Martínez, M. J. (2016). El proceso de independencia de Cataluña: su visión desde la Comunidad Valenciana. Teoría y realidad constitucional, 37, 381-404.

Rodríguez Jiménez, J. L. (2006). De la vieja a la nueva extrema derecha (pasando por la fascinación por el fascismo). Historia Actual Online, 9, 87-99.

Rodríguez Jiménez, J. L. (2012). Historia de un fracaso y ¿de una refundación?: De la vieja a la nueva extrema derecha en España (1975-2012). Studia Historica. Historia Contemporánea, 30, 231-268.

Sánchez Duarte, J. M. i Rodríguez Esperanza, S. (2013). La extrema-derecha en Facebook: España 2000 y Democracia Nacional durante la campaña electoral de 2011. Revista Mediterránea de Comunicación, 4(1), 221-258.

Sanz, Jesús (1982). La cara secreta de la política valenciana. València: Fernando Torres.

Sauer, B. i Pingaud, E. (2016). Framing Differences: Theorising New Populist Communicative Strategies on the Internet. En M. Ranieri (ed.), Populism, Media and Education: Challenging Discrimination in Contemporary Digital Societies (p. 26-43). Abingdon, Nova York: Routledge.

Schmitt Beck, R. (2017). The 'Alternative für Deutschland in the electorate': Between Single-issue and Right-wing Populist Party. German Politics, 26(1), 124-148.

Staykova, E., Otova, I. i Ivanova, V. (2016). Anti-elitism as a populist strategy of defending 'the people'. En M. Ranieri (ed.), Populism, Media and Education: Challenging Discrimination in Contemporary Digital Societies (p. 105-123). Abingdon, Nova York: Routledge. 
Strömbäck, J. (2008). Four Phases of Mediatization: An Analysis of the Mediatization of Politics. The International Journal of Press/Politics, 13(3), 228-246.

Trimble, L. i Sampert, S. (2004). Who's in the Game? The Framing of the Canadian Election 2000 by the Globe and Mail and the National Post. Canadian Journal of Political Science / Revue canadienne de science politique, 37(1), 51-71.

Valentino, N., Beckmann, M. i Buhr, T. (2001). A Spiral of Cynicism for Some: The Contingent Effects of Campaign News Frames on Participation and Confidence in Government. Political Communication, 18(4), 347-367.

Valera Ordaz, L., Carratalá, A. i Palau Sampio, D. (2017). La batalla de los partidos por la definición de la realidad: Los marcos partidistas durante las elecciones generales de 2015. En G. López García i L. Valera Ordaz (ed.), Pantallas electorales: El discurso de partidos, medios y ciudadanos en la campaña de 2015 (p. 59-78). Barcelona: Editorial UOC.

Van der Brug, W. i Mughan, A. (2007). Charisma, Leader Effects and Support for Right-wing Populist Parties. Party Politics, 13(1), 29-51.

Van Dijk, T. A. i Rodrigo Mendizábal, I. (1999). Análisis del discurso social y político. Quito: Abya-Yala.

Viadel, F. (2006). No mos fareu catalans: Història inacabada del "blaverisme". Barcelona: L'esfera dels llibres.

Xambó, R. (1995). Dies de premsa. València: L'Eixam Edicions.

Xambó, R. (2001). Comunicació, política i societat: El cas valencià. València: Edicions 3i4.

Xicoy, E., Perales García, C. i Xambó, R. (2017). Shaping Public Opinion for Confrontation: Catalan Independence Claims as Represented in Spanish, Catalan, Valencian, and Basque Editorials. American Behavioral Scientist, 61(9), 1040-1055.

\section{NOTA BIOGRÀFICA}

\section{Adolfo Carratalá}

Professor contractat doctor de Periodisme a la Universitat de València. És llicenciat en Periodisme i doctor en Comunicació. Prèviament, ha treballat com a investigador postdoctoral a la Universidad Rey Juan Carlos i com a professor associat a la Universidad Internacional de La Rioja. Les seues principals línies de recerca són periodisme i conflictes socials, i estudis LGTBI aplicats als mitjans de comunicació.

\section{Dolors Palau Sampio}

Professora titular de Periodisme de la Universitat de València. És llicenciada i doctora en Periodisme per la Universitat Autònoma de Barcelona. Va treballar durant nou anys al diari Levante-EMV. Les seues principals línies de recerca són la qualitat periodística i el periodisme digital i narratiu. 